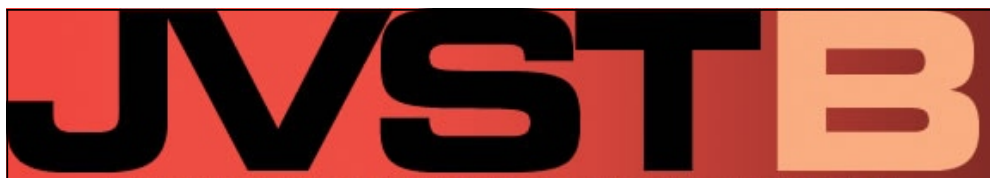

JOURNAL OF VACUUM SCIENCE AND TECHNOLOGY B

\title{
Optimization of in situ plasma oxidation of metallic gadolinium thin films deposited by high pressure sputtering on silicon
}

María Ángela Pampillón, Pedro Carlos Feijoo, Enrique San Andrés, and María Luisa Lucía

Citation: J. Vac. Sci. Technol. B 31, 01A112 (2013); doi: 10.1116/1.4769893

View online: http://dx.doi.org/10.1116/1.4769893

View Table of Contents: http://avspublications.org/resource/1/JVTBD9/v31/i1

Published by the AVS: Science \& Technology of Materials, Interfaces, and Processing

\section{Related Articles}

Tungstate formation in a model scandate thermionic cathode

J. Vac. Sci. Technol. B 31, 011210 (2013)

The Si3N4/TiN Interface: 3. Si3N4/TiN(001) Grown with a -150 V Substrate Bias and Analyzed In situ using Angle-resolved X-ray Photoelectron Spectroscopy

Surf. Sci. Spectra 19, 52 (2012)

Atomic layer deposition of cobalt oxide thin films using cyclopentadienylcobalt dicarbonyl and ozone at low temperatures

J. Vac. Sci. Technol. A 31, 01A145 (2013)

The Si3N4/TiN Interface: 4. Si3N4/TiN(001) Grown with a -250 V Substrate Bias and Analyzed In situ using Angle-resolved X-ray Photoelectron Spectroscopy

Surf. Sci. Spectra 19, 62 (2012)

Characterization of HfO2/La2O3 layered stacking deposited on Si substrate

J. Vac. Sci. Technol. B 31, 01A113 (2013)

\section{Additional information on J. Vac. Sci. Technol. B}

Journal Homepage: http://avspublications.org/jvstb

Journal Information: http://avspublications.org/jvstb/about/about_the_journal

Top downloads: http://avspublications.org/jvstb/top_20_most_downloaded

Information for Authors: http://avspublications.org/jvstb/authors/information_for_contributors

\section{ADVERTISEMENT}

\section{Instruments for advanced science}
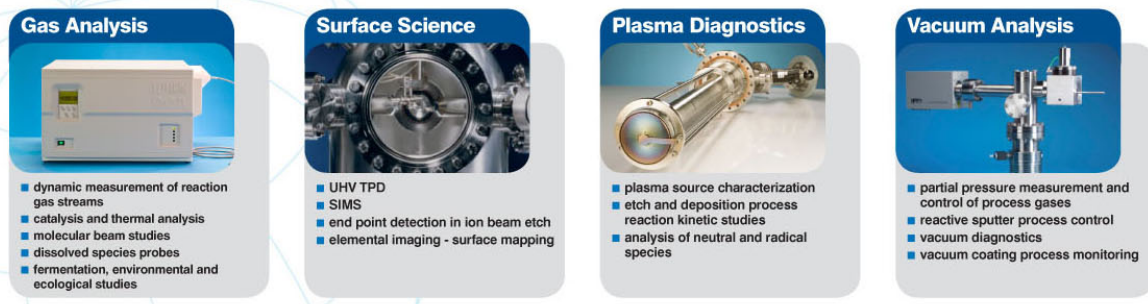

contact Hiden Analytical for further details

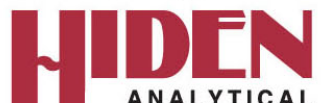

info@hideninc.com

www.HidenAnalytical.com

CLICK to view our product catalogue 


\title{
Optimization of in situ plasma oxidation of metallic gadolinium thin films deposited by high pressure sputtering on silicon
}

\author{
María Ángela Pampillón, ${ }^{\text {a) }}$ Pedro Carlos Feijoo, Enrique San Andrés, and María Luisa Lucía \\ Departamento de Física Aplicada III (Electricidad y Electrónica), Facultad de Ciencias Físicas, \\ Universidad Complutense de Madrid, E-28040 Madrid, Spain
}

(Received 30 July 2012; accepted 20 November 2012; published 7 December 2012)

\begin{abstract}
Gadolinium oxide thin films were deposited on silicon by a two-step process: high pressure sputtering from a metallic gadolinium target followed by an in situ plasma oxidation. Several plasma conditions for metal deposition and oxidation were studied in order to minimize the growth of a $\mathrm{SiO}_{\mathrm{x}}$ layer at the interface between the high permittivity dielectric and the silicon substrate and to avoid substrate damage. Plasma emission was studied with glow discharge optical spectroscopy. The films were structurally characterized by Fourier transform infrared spectroscopy. Metal-insulator-semiconductor capacitors were fabricated with two different top metals (titanium and platinum) to analyze the influence of deposition conditions and the metal choice. Pt gated devices showed an interfacial $\mathrm{SiO}_{\mathrm{x}}$ regrowth after a forming gas annealing, while Ti gates scavenge the interface layer. @ 2013 American Vacuum Society. [http://dx.doi.org/10.1116/1.4769893]
\end{abstract}

\section{INTRODUCTION}

To increase switching speed and integration density, the microelectronics industry needs to scale down the metaloxide-semiconductor field effect transistors (MOSFETs). For this reason, high permittivity (high $k$ ) dielectrics were introduced in complementary MOS routes. ${ }^{1}$ These high $k$ materials must meet several requirements ${ }^{2,3}$ such as thermal and chemical stability in contact with the semiconductor substrates and with the gate metals during the fabrication process. They must also have a $k$ value in the 10-30 range and a band gap larger than $5 \mathrm{eV}$. A low density of interfacial states is needed in order to avoid mobility degradation of the MOSFET. Finally, the regrowth of an undesirable interfacial $\mathrm{SiO}_{\mathrm{x}}$ film should be minimized, since it would reduce the effective permittivity of the stack and increase the equivalent oxide thickness (EOT).

For future high $k$ generations, rare earth scandates are promising candidates. ${ }^{4,5}$ Among them, $\mathrm{GdScO}_{3}$ shows adequate properties: ${ }^{6-8}$ a $k$ value up to $20,{ }^{6}$ greater than its binary constituents: $\mathrm{Sc}_{2} \mathrm{O}_{3}(k \sim 13)^{9}$ and $\mathrm{Gd}_{2} \mathrm{O}_{3}(k \sim 17),{ }^{10} \mathrm{a}$ band gap larger than $5 \mathrm{eV} .^{11,12}$ Additionally, some reports show that the films, in contact with $\mathrm{Si}$, remain amorphous up to $1000^{\circ} \mathrm{C}$.

This work is focused on the study of the properties of $\mathrm{Gd}_{2} \mathrm{O}_{3}$, obtained by high pressure sputtering (HPS) together with in situ plasma oxidation. This is the first step toward the combination with $\mathrm{Sc}$ to produce $\mathrm{GdScO}_{3}$. Several groups are researching the properties of high $k$ materials deposited by different techniques: metal-organic chemical vapor deposition, ${ }^{8}$ atomic layer deposition, ${ }^{13}$ pulsed laser deposition, ${ }^{4}$ electron beam evaporation, ${ }^{6,7}$ reactive sputtering, ${ }^{14}$ etc. Yet, except for our group, there is no information reported on HPS for these materials. Working with an HPS system prevents surface damage, due to the high deposition pressure, typically in the mbar range (between 2 and 3 orders of

$\overline{{ }^{a} \text { Electronic mail: mpampillon@ fis.ucm.es }}$ magnitude higher than conventional sputtering). This results in a lower mean free path of particles compared with conventional systems so that particles suffer many collisions and get thermallized before they can reach the substrate. ${ }^{15}$ In this work, with the aim to the fulfillment of the requirements for high $k$ integration, we have first deposited by HPS metallic thin films on Si from a pure Gd target in an Ar atmosphere. Then, without extracting the sample from the system, we have oxidized the films in situ through plasma oxidation just by changing plasma composition. Several plasma conditions were studied for metal deposition and plasma oxidation. With this two-step deposition process, we have aimed to minimize plasma damage of the surface during deposition and avoid an uncontrolled growth of $\mathrm{SiO}_{\mathrm{x}}$ at the high $k$ dielectric/Si interface. ${ }^{16}$ This low $k$ thin film would impose a lower limit to the total EOT that could be obtained. Carrying out the plasma oxidation of the metallic films in situ avoids the contamination of the high $k$ material.

Furthermore, we have studied the effect of different top metals: platinum, which is a noble metal and would not react with the high $k$ dielectric, and titanium, an oxygen scavenger. ${ }^{17}$

\section{EXPERIMENT}

The substrates used were 2 in. n-type (100) Si wafers with two different resistivities: $\mathrm{Si}$ polished on both sides and with high resistivity $(\sim 1100-3000 \Omega \mathrm{cm})$ for absorption measurements and single side polished $\mathrm{Si}$ with resistivity from 1.5 to $5 \Omega \mathrm{cm}$ for electrical characterizations. Low resistivity substrates were cleaned by the standard RCA (Radio Corporation of America) process. ${ }^{18}$ All wafers were etched in diluted hydrofluoric acid (HF) (1:50) for $30 \mathrm{~s}$ just before introducing them into the HPS chamber for native $\mathrm{SiO}_{\mathrm{x}}$ removal. When the pressure was in the $10^{-5} \mathrm{mbar}$ range, the substrates were heated to $500{ }^{\circ} \mathrm{C}$ during $5 \mathrm{~min}$ for surface desorption. Before deposition, the system was evacuated to a pressure below $10^{-6}$ mbar.

The $\mathrm{Gd}_{2} \mathrm{O}_{3}$ films were grown by a two-step process. First, a metallic Gd thin film was deposited on Si by HPS in a pure 
Ar atmosphere from a Gd target. This target has a purity of $99.9 \%$, a diameter of $2 \mathrm{in}$., and a thickness of $1 / 8 \mathrm{in}$. The plasma pressure was varied between 0.25 and $1.0 \mathrm{mbar}$ and the radiofrequency $(r f)$ power from 10 to $30 \mathrm{~W}$. The metal deposition in pure Ar atmosphere aims to avoid the growth of $\mathrm{SiO}_{\mathrm{x}}$ at the interface between $\mathrm{Si}$ and the high $k$ dielectric. Due to the high deposition rate, the Gd layer covers the $\mathrm{Si}$ surface in the very first stages of the deposition, reducing plasma damage to the semiconductor surface. Once the metal deposition conditions were studied, plasma pressure and $r f$ power were fixed to $0.50 \mathrm{mbar}$ and $30 \mathrm{~W}$, respectively. The deposition time used for device fabrication was 80 s. These conditions produce a $\sim 4 \mathrm{~nm}$ thick $\mathrm{Gd}_{2} \mathrm{O}_{3}$ layer after oxidation. To perform the oxidation of the metallic film, a 5\% flux of oxygen was introduced into the chamber; in other words, the atmosphere was changed from inert to reactive. Several plasma oxidation conditions were analyzed by changing the applied $r f$ power $(10,20$, or $30 \mathrm{~W})$ and the oxidation time $(150,225$, or $300 \mathrm{~s})$. Also, in order to study the effect of modifying the starting Gd thickness, the metal deposition time was changed to 120 and $160 \mathrm{~s}$ to obtain thicker films. All processes were carried out at room temperature. Plasma was generated by a Huttinger $300 \mathrm{rf}$ generator with an excitation frequency of $13.56 \mathrm{MHz}$. Glow discharge optical spectroscopy (GDOS) was performed to study Gd deposition and oxidation conditions with an automated Jobin-Ybon monocromator coupled to a photomultiplier. With this system, wavelengths from 200 to $800 \mathrm{~nm}$ can be scanned. We focused on the range between 280 and $520 \mathrm{~nm}$, where the most important emission lines of $\mathrm{Ar}$ and $\mathrm{Gd}$ are observed.

The bonding structure of the $\mathrm{Gd}_{2} \mathrm{O}_{3}$ films was analyzed by Fourier transform infrared (FTIR) spectroscopy using a Nicolet Magna-IR 750 Series II spectrometer working in transmission mode at normal incidence. In the same session, it was measured a bare $\mathrm{Si}$ substrate etched in diluted HF for $30 \mathrm{~s}$, just before the measurement, for substrate signal correction. Therefore, the $\mathrm{Gd}_{2} \mathrm{O}_{3}$ layer and interface absorbance were obtained by subtracting the $\mathrm{Si}$ substrate contribution from the total $\mathrm{Gd}_{2} \mathrm{O}_{3} / \mathrm{SiO}_{\mathrm{x}} / \mathrm{Si}$ absorbance.

For the electrical characterization, MIS devices were fabricated by defining square openings (with an area varying from $630 \times 630$ to $100 \times 100 \mu \mathrm{m}^{2}$ ) with a negative resist n-LOF 2035 lithographic process on top of the dielectric. To guarantee that the dielectric was identical for different top metals (inert and oxygen scavenger), the wafer was cut into four quarters. Each piece was electron beam evaporated with two different metal stacks: $24 \mathrm{~nm}$ of Pt (in three steps of $8 \mathrm{~nm}$ each with a $30 \mathrm{~min}$ cooling time between steps to avoid adhesion problems) and $100 \mathrm{~nm}$ of Ti. This way, with the nonreactive Pt electrodes, the bare properties of the high $k$ could be studied, while Ti electrodes were used for studying the oxygen scavenging effect. Both metal layers were capped with $\mathrm{Al}$ (in the case of $\mathrm{Pt}$, to avoid structural degradation when probing and for $\mathrm{Ti}$, to prevent surface oxidation or nitridation). Then, each piece was lifted off and a Ti $100 \mathrm{~nm} / \mathrm{Al}$ $200 \mathrm{~nm}$ backside ohmic contact was evaporated. Finally, a forming gas annealing (FGA) at $300^{\circ} \mathrm{C}$ for 20 min was carried out in a Modular Process Technology 600 furnace. Capacitance and conductance as a function of gate voltage were measured in a Faraday cage setup with an Agilent $4294 \mathrm{~A}$ impedance meter at a frequency of $10 \mathrm{kHz}$. The density of interfacial states $\left(D_{i t}\right)$ was evaluated by the conductance method, ${ }^{19}$ whereas the EOT value was obtained by the Hauser algorithm. ${ }^{20}$

\section{RESULTS AND DISCUSSION}

First of all, a study of the species present in the plasma was carried out using GDOS in order to obtain the optimal sputtering conditions for metallic Gd deposition. Figure 1 presents plasma spectra for different pressures with $r f$ power fixed at $30 \mathrm{~W}$. Lines between 290 and $410 \mathrm{~nm}$ are in agreement with Gd I (nonionized Gd) and Gd II (singly ionized) transitions. ${ }^{21}$ However, the most important emission lines of Ar I and Ar II are in the 400-450 nm and 450-490 nm ranges, respectively. ${ }^{22}$ For 0.25 mbar [Fig. 1(a)], Gd extraction is very small, likely due to the scarce presence of ionized Ar. Spectra for 0.50 and 0.75 mbar [Figs. 1(b) and 1(c)] are similar: it can be observed a great number of emission lines corresponding to Ar I and Ar II and also a large increase in Gd I and Gd II peaks. The maximum relative intensity of Gd transitions corresponds to these pressures. As it can be seen in Fig. 1(d), the Gd peaks decrease for $1.0 \mathrm{mbar}$. Moreover, the plasma above this pressure presents instabilities. Therefore, it was decided to work at 0.50 mbar to have the maximum deposition rate and the minimal gas consumption of the system and, also, to avoid problems with plasma instabilities. Other works ${ }^{23}$ that studied HPS of oxides showed that deposition rate decreased with pressure, and that 0.50 mbar presented the best compromise between efficient extraction and deposition rate, as these results confirm for metallic deposition.

Once the optimum work pressure was determined, it had to be optimized the $r f$ power. Figure 2 shows GDOS spectra for $r f$ power values of 10,20 , and $30 \mathrm{~W}$. At $10 \mathrm{~W}$, some lines corresponding to Ar I appear but no presence of $\mathrm{Ar}$ II, Gd I, or Gd II is found. When the power increases, many Ar I and Ar II peaks become visible. Those peaks suggest the

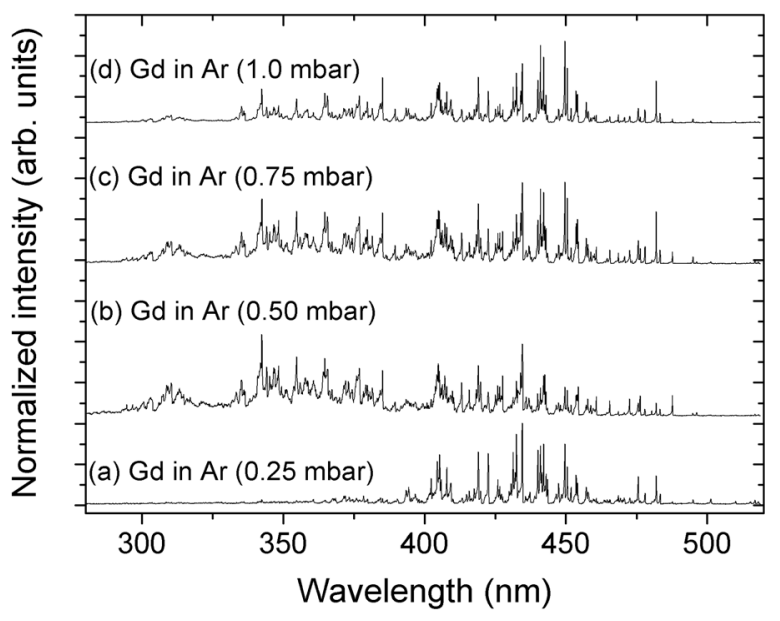

FIG. 1. Optical spectra of sputtered Gd in an Ar atmosphere at $30 \mathrm{~W}$ of $r f$ power and different pressures: (a) 0.25, (b) 0.50, (c) 0.75, and (d) 1.0 mbar. 


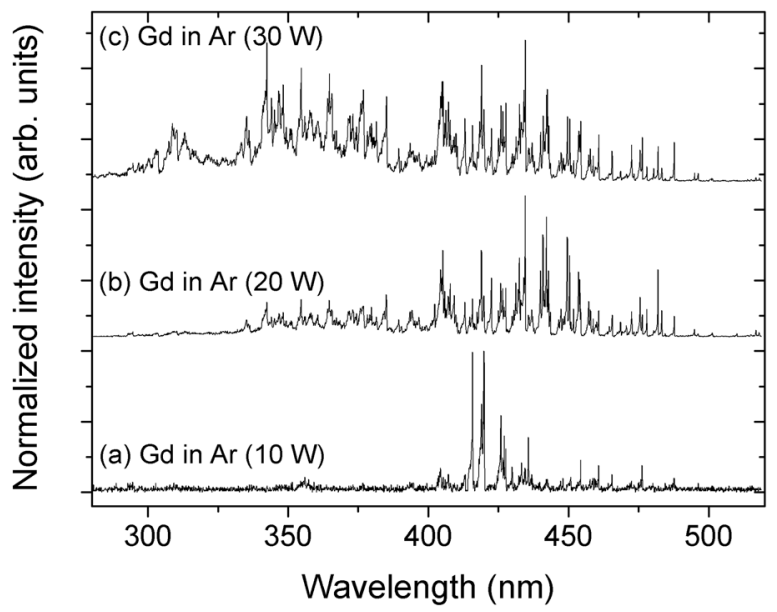

FIG. 2. Optical spectra of sputtered Gd in an Ar plasma at a pressure of 0.50 mbar and different $r f$ powers: (a) 10, (b) 20, and (c) $30 \mathrm{~W}$.

extraction of Gd from the target, being stronger for $30 \mathrm{~W}$. So, to ensure a high growth rate, it was decided to work at $30 \mathrm{~W}$. Higher power might produce plasma damage in the substrate surface and higher deposition rates were not needed. Thus, $r f$ power was not increased above $30 \mathrm{~W}$.

Figure 3 represents GDOS spectra of Gd sputtered in an $\mathrm{Ar} / \mathrm{O}_{2}$ plasma (with a 95/5\% ratio) for different $r f$ power values. Only peaks near $390 \mathrm{~nm}$ could be related to O I and O II. However, those lines are also present in the spectrum of metallic Gd sputtered in pure Ar atmosphere. Therefore, we cannot ensure the presence of emission lines of O I and O II in this plasma because they would be mixed with $\mathrm{Ar}$ and $\mathrm{Gd}$ lines. In the same HPS system when sputtering $\mathrm{HfO}_{2}$, it was only possible to distinguish unambiguously lines belonging to oxygen (O I and $\mathrm{O}$ II) when working in a pure reactive oxygen atmosphere. ${ }^{24}$ When sputtering in Ar plasma, no oxygen related emission was identified, although the resulting films were stoichiometric. Comparing Figs. 2(a) and 3(a), it can be observed that for $10 \mathrm{~W}$ the number and intensity of emission lines corresponding to $\mathrm{Ar}$ II are reduced in the case of the $\mathrm{Ar} / \mathrm{O}_{2}$ atmosphere compared to pure Ar plasma. As the power increases, the differences between Figs. 2 and 3

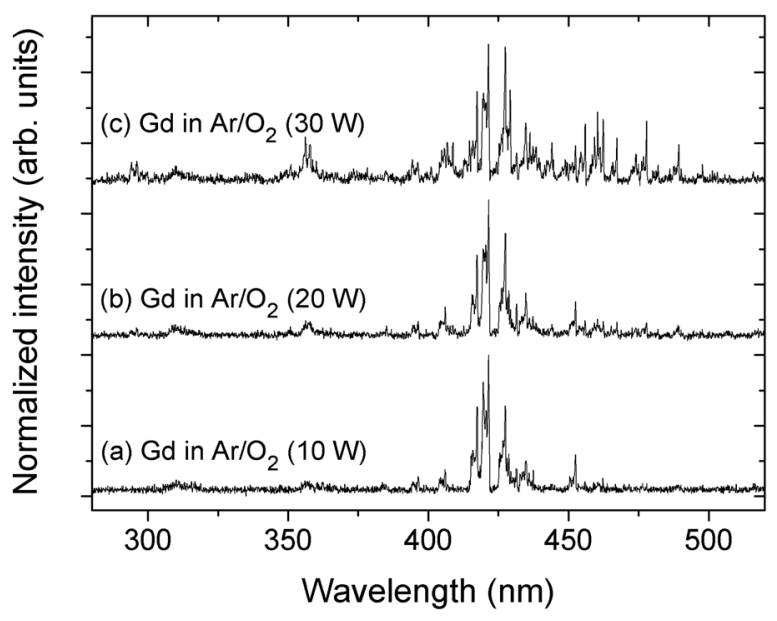

FIG. 3. Optical spectra of $\mathrm{Gd}$ in an $\mathrm{Ar} / \mathrm{O}_{2}$ atmosphere (95/5 ratio) at a pressure of 0.50 mbar and different $r f$ powers: (a) 10 , (b) 20 , and (c) $30 \mathrm{~W}$. become more evident. When a small amount of oxygen is introduced into the chamber, the lines corresponding to Ar I and Ar II are reduced and, specifically, those belonging to Gd I and Gd II disappear. This is an indication that the introduction of oxygen into the chamber reduces the extraction of $\mathrm{Gd}$, as we reported in a previous work. ${ }^{25}$

In order to improve the electrical characteristics of the sputtered $\mathrm{Gd}_{2} \mathrm{O}_{3}$ films and to reduce the growth of interfacial $\mathrm{SiO}_{\mathrm{x}}$, the properties of the grown films were studied as a function of the plasma oxidation conditions. A thin film of Gd was deposited in Ar atmosphere during $80 \mathrm{~s}$ at the optimal $r f$ power of $30 \mathrm{~W}$ and $0.50 \mathrm{mbar}$ of pressure. Subsequently, an in situ plasma oxidation was performed by varying the oxidation parameters. The base process was at $30 \mathrm{~W}$ of $r f$ power, 0.50 mbar of pressure, and $300 \mathrm{~s}$ of oxidation duration. To study the effect of parameter variation, samples were fabricated by varying the oxidation power and, also, the oxidation time. Additionally, with the purpose of completing the study, a variation of the metallic Gd deposition time, to obtain thicker $\mathrm{Gd}_{2} \mathrm{O}_{3}$ films, was performed.

\section{A. Oxidation power}

Figure 4 presents FTIR absorbance spectra in the range of $900-1200 \mathrm{~cm}^{-1}$ for samples oxidized with different plasma $r f$ power values. A peak centered at $\sim 1040 \mathrm{~cm}^{-1}$ can be observed, which is related to substoichiometric $\mathrm{SiO}_{\mathrm{x}} \cdot{ }^{26-28} \mathrm{It}$ is noteworthy that the backside of the samples is bare $\mathrm{Si}$, so part of this signal might be due to the backside native oxide. However, since all samples followed similar processing, this oxide should be similar and FTIR results can be used, at least, to give qualitative information about interfacial $\mathrm{SiO}_{\mathrm{x}}$ thickness. For samples oxidized at 10 and $20 \mathrm{~W}$, the intensity of the $\mathrm{SiO}_{\mathrm{x}}$ band is similar but increases for the sample oxidized at $30 \mathrm{~W}$. In the inset of this figure, which represents the peak area as a function of oxidation power, it can be quantitatively observed the increase in the $\mathrm{SiO}_{\mathrm{x}}$ thickness for $30 \mathrm{~W}$. This is an indication that there is some regrowth of interfacial $\mathrm{SiO}_{\mathrm{x}}$ for this power.

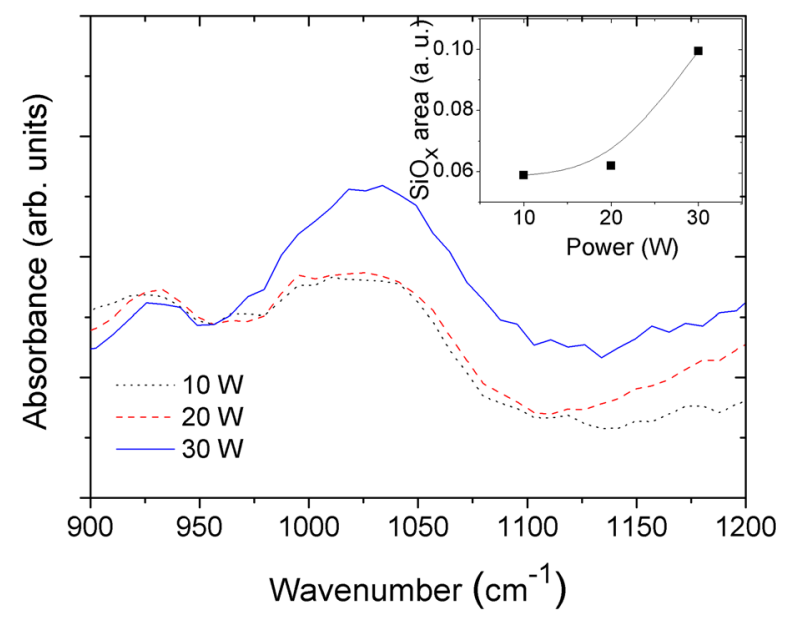

FIG. 4. (Color online) FTIR spectra for samples with different oxidation $r f$ power: 10,20 , and $30 \mathrm{~W}$. Inset: $\mathrm{SiO}_{\mathrm{x}}$ area as a function of $r f$ power. 
Figure 5 depicts the normalized capacitance of MIS capacitors as a function of the gate voltage for two different electrodes: Pt [Figs. 5(a) and 5(c)] and Ti [Figs. 5(b) and 5(d)]. Results for as grown devices and after FGA are shown. As expected, before FGA the effect of the top metal is not noticeable in the capacitance value. For both metals, samples processed with $20 \mathrm{~W}$ of oxidation power present the highest value of the capacitance. This suggests an excessive oxidation (interfacial $\mathrm{SiO}_{\mathrm{x}}$ regrowth) at $30 \mathrm{~W}$, while at $10 \mathrm{~W}$ the Gd film is not completely oxidized, yielding a lower $k$ film. Also, an important difference can be observed between the metals after the FGA: the capacitance of Ti gated MIS devices increases while for Pt gated samples decreases. The rise of the capacitance value is a consequence of the scavenging effect of $\mathrm{Ti}$, which removes oxygen from the interfacial layer of $\mathrm{SiO}_{\mathrm{x}} \cdot{ }^{17,25}$ For an oxidation power of $20 \mathrm{~W}$, the EOT for Ti devices is reduced from 2.5 to $1.6 \mathrm{~nm}$. In Pt samples, the fall in the capacitance could be due to an $\sim 1.3 \mathrm{~nm}$ oxide growth or Pt adhesion problems that reduce the effective electrode area (some bubbling was found in the devices). ${ }^{29}$ Additionally, capacitance curves present a hump in $\mathrm{Ti}$ samples after the FGA, which is caused by a higher
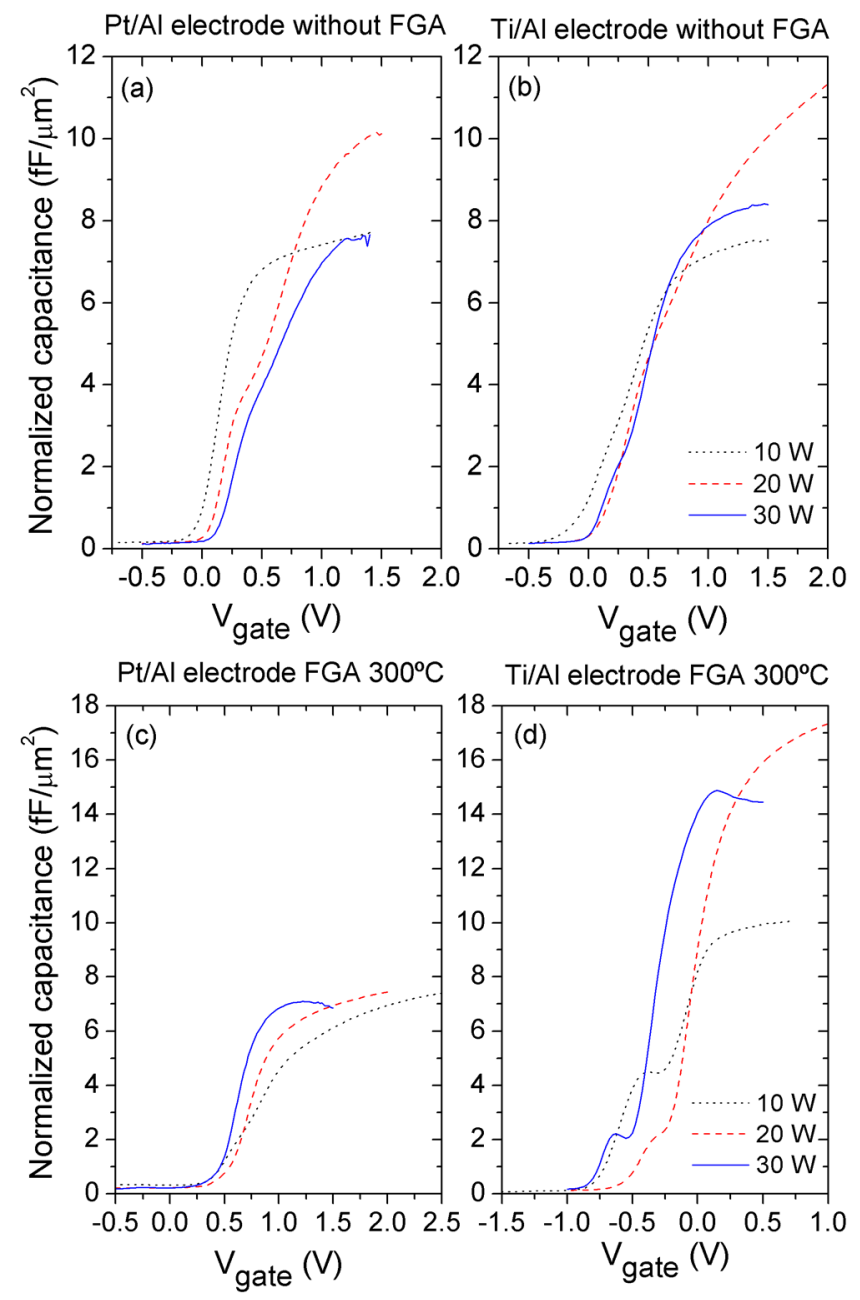

FIG. 5. (Color online) Normalized capacitance as a function of the gate voltage for two different electrodes: Pt [(a) and (c)] and Ti [(b) and (d)], as well as before the FGA [(a) and (b)] and after [(c) and (d)] for samples with different oxidation $r f$ power: 10,20 , and $30 \mathrm{~W}$.
$D_{i t}\left(\sim 10^{12} \mathrm{eV}^{-1} \cdot \mathrm{cm}^{-2}\right.$, about 1 order of magnitude higher than Pt samples). This is not surprising, since Ti scavenges the $\mathrm{SiO}_{\mathrm{x}}$ interface, and the resulting surface can be very defective. This effect was found in other works that use Ti. ${ }^{30}$ This implies that for device integration, Ti electrode should be removed after EOT optimization and the structure should be annealed afterwards, in a gate-last like approach.

\section{B. Oxidation time}

As the oxidation time is increased from 150 to $300 \mathrm{~s}$, the area of the $\mathrm{SiO}_{\mathrm{x}}$ band observed in the FTIR spectra also increases, as shown in Fig. 6. This could be explained as follows: when the oxygen is introduced into the chamber, Gd oxidation starts for the upper layers, and then oxygen diffuses. When the entire $\mathrm{Gd}$ thin film is oxidized, $\mathrm{O}_{2}$ reaches the $\mathrm{Si}$ substrate and oxidizes the $\mathrm{Si}$, producing an interfacial $\mathrm{SiO}_{\mathrm{x}}$ layer. Thus, longer oxidation times increase the $\mathrm{SiO}_{\mathrm{x}}$ thickness between silicon and the high $k$ material.

Capacitance values experiment the same effect due to the FGA explained in the former section: in Pt gated samples, the capacitance is reduced, while in Ti gated devices, it is increased. Furthermore, the trend obtained for both metals is that lower oxidation duration provides higher capacitance values. This suggests that with these plasma conditions, $150 \mathrm{~s}$ is a time long enough to completely oxidize the metallic Gd film. Then, increasing the oxidation time leads to the growth of a thicker low $k \mathrm{SiO}_{\mathrm{x}}$. Since it behaves as a series capacitance, the EOT would increase. EOT and $D_{i t}$ values of these samples are presented in Table I. For Pt samples after FGA, since no appreciable conductance peak could be observed, it can be concluded that the density of states was under the detection limit, due to hydrogen passivation.

\section{Metal deposition time}

Now, the influence of the initial thickness of metallic Gd on the properties of the $\mathrm{Gd}_{2} \mathrm{O}_{3}$ layer obtained after plasma oxidation is discussed. The FTIR spectra of these samples are shown in Fig. 7. For 120 and $160 \mathrm{~s}$ of metal deposition

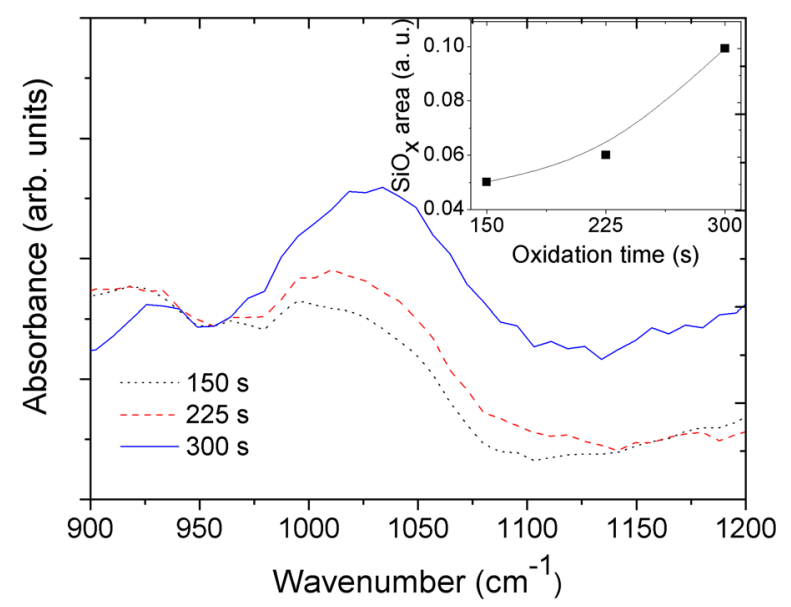

FIG. 6. (Color online) FTIR spectra for samples with different oxidation duration: 150,225 , and $300 \mathrm{~s}$. Inset: $\mathrm{SiO}_{\mathrm{x}}$ area as a function of oxidation duration for the same samples. 
TABLE I. EOT and $D_{i t}$ values of samples with different oxidation time before and after FGA for Ti and Pt as top metal.

\begin{tabular}{|c|c|c|c|c|c|c|c|c|}
\hline \multicolumn{5}{|c|}{ Before FGA } & \multicolumn{4}{|c|}{ After FGA } \\
\hline \multirow[b]{2}{*}{ Sample (s) } & \multicolumn{2}{|c|}{ EOT (nm) } & \multicolumn{2}{|c|}{$D_{i t}\left(\mathrm{eV}^{-1} \mathrm{~cm}^{-2}\right)$} & \multicolumn{2}{|c|}{ EOT (nm) } & \multicolumn{2}{|c|}{$D_{i t}\left(\mathrm{eV}^{-1} \mathrm{~cm}^{-2}\right)$} \\
\hline & $\mathrm{Pt} / \mathrm{Al}$ & $\mathrm{Ti} / \mathrm{Al}$ & $\mathrm{Pt} / \mathrm{Al}$ & $\mathrm{Ti} / \mathrm{Al}$ & $\mathrm{Pt} / \mathrm{Al}$ & $\mathrm{Ti} / \mathrm{Al}$ & $\mathrm{Pt} / \mathrm{Al}$ & $\mathrm{Ti} / \mathrm{Al}$ \\
\hline 150 & 3.0 & 2.6 & $2 \times 10^{12}$ & $2 \times 10^{12}$ & 3.4 & 1.5 & - & $4 \times 10^{12}$ \\
\hline 225 & 3.0 & 3.2 & $2 \times 10^{12}$ & $2 \times 10^{12}$ & 3.7 & 1.6 & - & $3 \times 10^{12}$ \\
\hline 300 & 3.8 & 3.5 & $5 \times 10^{12}$ & $1 \times 10^{12}$ & 4.0 & 1.7 & - & $1 \times 10^{12}$ \\
\hline
\end{tabular}

time, the peak of $\mathrm{SiO}_{\mathrm{x}}$ is shifted to lower wavenumbers and it is centered in $\sim 1020 \mathrm{~cm}^{-1}$, indicating stressed $\mathrm{SiO}_{2}$ or suboxide formation. ${ }^{31}$ Additionally, for the longer deposition times, the bands are similar in shape and area. However, the peak area for $80 \mathrm{~s}$ is slightly higher, as it can be seen in the inset of the figure. This points to the result that longer metal deposition time leads to a lower interfacial $\mathrm{SiO}_{\mathrm{x}}$ thickness.

In Fig. 8, the electrical behavior for these samples is represented. $\mathrm{C}-\mathrm{V}$ curves for both metals and after the FGA [Figs. 8(a) and 8(b)] show the important differences in the capacitance value for $\mathrm{Ti}$ gated devices as compared to the $\mathrm{Pt}$ ones. Furthermore, for $\mathrm{Ti}$ samples, a thicker $\mathrm{Gd}$ layer resulted in a decrease of the capacitance and therefore an increase of the EOT: $1.7 \mathrm{~nm}$ for $80 \mathrm{~s}$, versus 1.9 and $2.7 \mathrm{~nm}$ for 120 and $160 \mathrm{~s}$, respectively. However, this trend is not observed in Pt devices probably due to the coupled effect of thicker $\mathrm{Gd}_{2} \mathrm{O}_{3}$ together with thinner $\mathrm{SiO}_{\mathrm{x}}$. This compensating effect is not found in $\mathrm{Ti}$, since the metal electrode scavenges part of the $\mathrm{SiO}_{\mathrm{x}}$ interface and then, the capacitance is mainly due to the $\mathrm{Gd}_{2} \mathrm{O}_{3}$, which is thicker for longer metal times. Additionally, G-V characteristics for both metals and after the FGA [Figs. 8(c) and 8(d)] present very low conductances for 120 and $160 \mathrm{~s}$ or, in other words, less gate leakage. With the conductance method, ${ }^{19}$ the $D_{i t}$ obtained is $5 \times 10^{10}$ $\mathrm{eV}^{-1} \mathrm{~cm}^{-2}$ for the Pt devices, and from $4 \times 10^{11}$ to $9 \times 10^{11}$ $\mathrm{eV}^{-1} \mathrm{~cm}^{-2}$ for Ti samples.

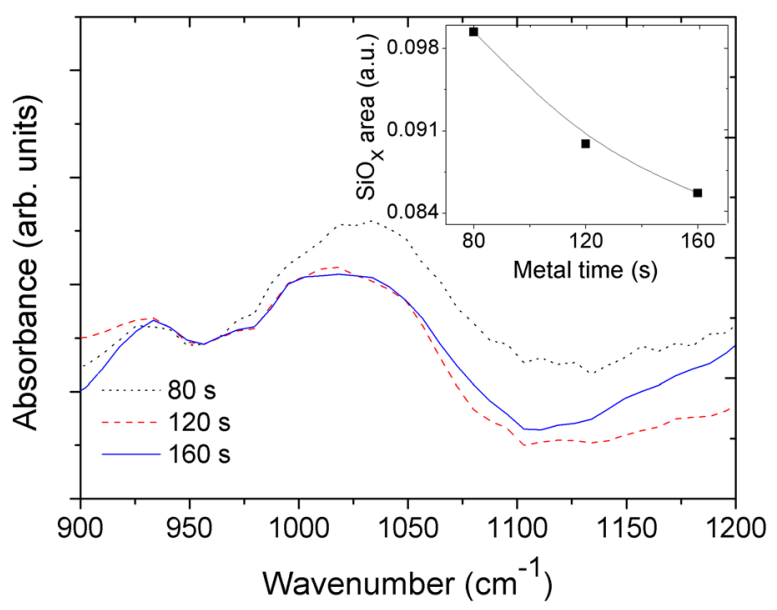

FIG. 7. (Color online) FTIR spectra for samples with different metal deposition time: 80,120 , and 160 s. Inset: $\mathrm{SiO}_{\mathrm{x}}$ area as a function of metal deposition time for the same samples.

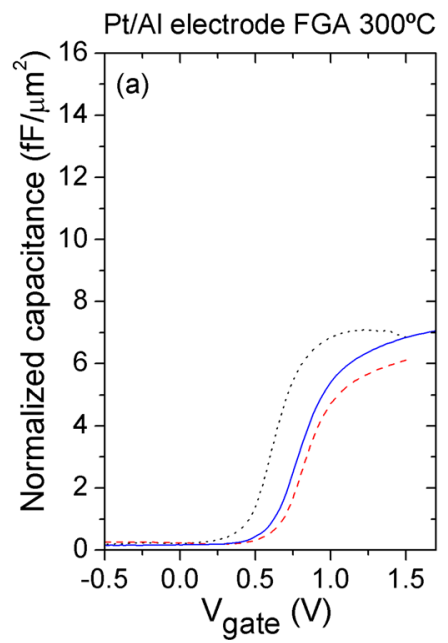

Ti/Al electrode FGA $300^{\circ} \mathrm{C}$

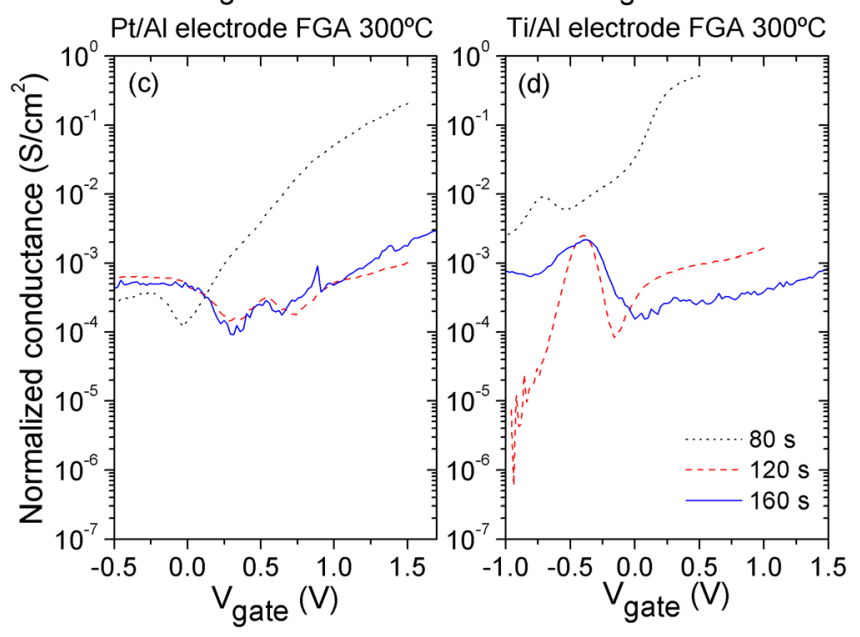

FIG. 8. (Color online) Normalized C-V $-V_{\text {gate }}\left[(a)\right.$ and (b)] and $G-V_{\text {gate }}[(\mathrm{c})$ and (d)] for samples with several metal deposition time: 80,120 , and $160 \mathrm{~s}$, after FGA with two different top metals: Pt [(a) and (c)] and Ti [(b) and (d)].

\section{SUMMARY AND CONCLUSIONS}

In this work, we studied $\mathrm{Gd}_{2} \mathrm{O}_{3}$ films deposited by HPS in a two-step process: first, metallic Gd films were sputtered in Ar and, then, we performed an in situ plasma oxidation in an $\mathrm{Ar} / \mathrm{O}_{2}$ atmosphere. We investigated several plasma conditions in order to obtain a minimal $\mathrm{SiO}_{\mathrm{x}}$ interfacial layer and avoid substrate damage. Finally, the effects of two different top metals were studied for electrical characteristics: for Ti gated MIS devices, we obtained an EOT reduction of $\sim 2 \mathrm{~nm}$, while Pt gated MIS capacitors showed an increment in this value. In the near future, this low damage process will be implemented on III-V substrates.

\section{ACKNOWLEDGMENTS}

The authors would like to acknowledge C.A.I. de Técnicas Físicas and C.A.I. de Espectroscopía y Espectrometría of the Universidad Complutense de Madrid. This work was funded by the Spanish Ministerio de Economía y Competividad through the project TEC2010-18051. Works of M. A. Pampillón and P. C. Feijoo were funded by the FPI program and FPU Grant No. AP2007-01157, respectively. 
${ }^{1}$ C. Auth et al., Intel Technol. J. 12, 77 (2008).

${ }^{2}$ G. D. Wilk, R. M. Wallace, and J. M. Anthony, J. Appl. Phys. 89, 5243 (2001).

${ }^{3}$ J. Robertson, Rep. Prog. Phys. 69, 327 (2006).

${ }^{4}$ C. Zhao et al., Appl. Phys. Lett. 86, 132903 (2005).

${ }^{5}$ J. M. J. Lopes et al., Microelectron. Eng. 86, 1646 (2009).

${ }^{6}$ M. Wagner, T. Heeg, J. Schubert, St. Lenk, S. Mantl, C. Zhao, M. Caymax, and S. De Gendt, Appl. Phys. Lett. 88, 172901 (2006).

${ }^{7}$ M. Roeckerath, J. M. J. Lopes, E. Durgun Özben, C. Sandow, S. Lenk, T. Heeg, J. Schubert, and S. Mantl, Appl. Phys. A: Mater. Sci. Process. 94, 521 (2009).

${ }^{8}$ K. Fröhlich, J. Fedor, I. Kostic, J. Manka, and P. Ballo, J. Electr. Eng. 62, 54 (2011)

${ }^{9}$ R. D. Shannon, J. Appl. Phys. 73, 348 (1993).

${ }^{10}$ J. A. Kittl et al., Microelectron. Eng. 86, 1789 (2009).

${ }^{11}$ S.-G. Lim et al., J. Appl. Phys. 91, 4500 (2002).

${ }^{12}$ V. V. Afanas'ev, A. Stesmans, C. Zhao, M. Caymax, T. Heeg, J. Schubert, Y. Jia, D. G. Schlom, and G. Lucovsky, Appl. Phys. Lett. 85, 5917 (2004).

${ }^{13}$ B. S. Lim, A. Rahtu, and R. G. Gordon, Nature Mater. 2, 749 (2003).

${ }^{14}$ G. He, M. Liu, L. Q. Zhu, M. Chang, Q. Fang, and L. D. Zhang, Surf. Sci. 576, 67 (2005).

${ }^{15}$ E. San Andrés, M. Toledano-Luque, A. del Prado, M. A. Navacerrada, I. Mártil, G. González-Díaz, W. Bohne, J. Röhrich, and E. Strub, J. Vac. Sci. Technol. A 23, 1523 (2005).

${ }^{16}$ Y. Hoshino, Y. Kido, K. Yamamoto, S. Hayashi, and M. Niwa, Appl. Phys. Lett. 81, 2650 (2002).
${ }^{17}$ H. Kim, P. C. McIntyre, C. O. Chui, K. C. Saraswat, and S. Stemmer, J. Appl. Phys. 96, 3467 (2004).

${ }^{18}$ W. Kern and D. Puotinen, RCA Rev. 31, 187 (1970).

${ }^{19}$ E. H. Nicollian and A. Goetzberger, At\&T Tech. J. 46, 1055 (1967).

${ }^{20}$ J. R. Hauser, cvc version 5.0, (C) 2000 NCSU Software, Department of Electrical and Computer Engineering, North Carolina State University, Raleigh, NC, 2000.

${ }^{21}$ W. F. Meggers, C. H. Corliss, and B. F. Scribner, Natl. Bur. Stand. Monograph 145, 600 (1975).

${ }^{22}$ G. Norlén, Phys. Scr. 8, 249 (1973).

${ }^{23}$ M. Toledano-Luque et al., J. Appl. Phys. 102, 044106 (2007).

${ }^{24}$ M. Toledano-Luque, M. L. Lucía, A. del Prado, E. San Andrés, I. Mártil, and G. González-Díaz, Appl. Phys. Lett. 91, 191502 (2007).

${ }^{25}$ M. A. Pampillón, P. C. Feijoo, E. San Andrés, M. Toledano-Luque, A. del Prado, A. J. Blázquez, and M. L. Lucía, Microelectron. Eng. 88, 1357 (2011).

${ }^{26}$ P. G. Pai, S. S. Chao, V. Takagi, and G. Lucovsky, J. Vac. Sci. Technol. A 4, 689 (1986).

${ }^{27}$ R. A. B. Devine, Appl. Phys. Lett. 68, 3108 (1996).

${ }^{28}$ A. C. Diebold, D. Venables, Y. Chabal, D. Muller, M. Weldon, and E. Garfunkel, Mater. Sci. Semicond. Process. 2, 103 (1999).

${ }^{29}$ E. Monroy et al., Semicond. Sci. Technol. 17, L47 (2002).

${ }^{30}$ Y. Morita, S. Migita, W. Mizubayashi, and H. Ota, Jpn. J. Appl. Phys., Part 1 50, 10PG01 (2011).

${ }^{31}$ E. San Andrés, A. del Prado, I. Mártil, G. González-Díaz, D. Bravo, and F. J. López, J. Appl. Phys. 92, 1906 (2002). 